CHATTERJEE, B. B., \& ERIKSEN, C. W. Cognitive factors in heart conditioning. Journal of Experimental Psychology, 1962, 64, 272-279.

COOK, S. W., HARRIS, R. E. Verbal conditioning of the galvanic skin response. Journal of Experimental Psychology, 1937, 21, 202-210.

EYSENCK, H. J. The biological basis of personality. Springfield, I11: Thomas, 1967.

FAHRENBERG, J., \& DELIUS, L. Eine Faktoren analyse psychischer und vegetativer Regulationsdaten. Nervenaryt. $1963,34,437-443$.

FUHREE, M. J., \& BAER, P. E. Differential classical conditioning: Verbalization of stimulus contingencies. Science, 1965. 150, 1479-1481.

GRINGS, W. W., CARLIN, S., \& APPLEY. $M$. Set, suggestion, and conditioning. Journal of Experimental Psychology. $1962,63,417-422$

GRINGS, W. W., \& ZEINER, A. Automatic response to words modified by sensitizing and conditioning experiences. Journal of
Psychosomatic Research, 1965, 8, 373-378.

MARTIN, R., DEAN, S., \& SHEAN, G. Selective attention and instrumental modification of the GSR. Psychophysiology, 1964, 4, 460-464.

MEDNICK, S. A. Learning. Englew ood Cliffs, N.J: Prentice-Hall, 1964.

MOWRER, O. H. Preparatory set: A determinant in motivation and learning Psychological Review, 1938, 45, 61-91.

SHEAN, G. D. The relationship between ability to verbalize stimulus contingencies and GSR conditioning. Journal of Psychosomatic Research, 1968a, 12. 245-249.

SHEAN, G. D. Vasomotor conditioning and awareness. Psychophysiology, 1968b, 5, 22-30.

SHEAN、G. D. Instrumental modification of the galvanic skin response: Conditioning or control? Journal of Psychosomatic Research, 1970, 14.

STERN, R. M. Operant conditioning of spontaneous GSR's: Negative results. Journal of Experimental Psychology, $1967,75,128-130$

\title{
Termination of a stressful task reduces fear of an approaching shock*
}

\author{
ALEXANDER HESS \\ Department of Behavioural Sciences \\ Tel-Aviv University Medical School, Tel-Aviv, Israel \\ and \\ SHLOMO BREZNITZ \\ Hebrew University, Jerusalem, Israel
}

An unavoidable electric shock was anticipated by $96 \mathrm{Ss}$ for $6 \mathrm{~min}$. Forty-eight of these were given another stressful task from Minute 4 to Minute $5 \frac{1 / 2}{2}$ of anticipation. It was found that, by terminating the stressful task 30 sec before the shock was due, Ss entered a relaxation phase and their heart rates revealed less fear of shock than that of the shock-only group.

There is some evidence that, when people anticipate an unavoidable frightening event, their fear reaction tends to follow a specific U-shaped pattern (Breznitz, 1967, 1968; Elliot, Bankart, \& Light, 1970). It is possible to analyze this pattern by dividing it into relevant psychological components. When the threat is first presented, there is a rise in measurable fear (Folkins, 1970); then follows a gradual relaxation, and finally, with the approach of the frightening event, the fear intensifies considerably. This particular pattern was found only with

* We are greatly indebted to Dr. Pinchas Yarden for his invaluable encouragement and to $S$. Biederman who helped at all stages of the research. situations in which the anticipation period was "empty" and the $S$ was passive.

We were interested in investigating the course of the fear reaction while the $S$, in addition to anticipating the frightening event, performs a stressful task. What would be the effect of this second stress upon the first one? What changes would take place in the temporal characteristics of the fear reaction? More specifically, what should one expect if the task is terminated before the execution of the initial threat? It is conceivable that the termination of one stress reduces tension, while, at the same time, the future frightening event is approaching, thus producing conflicting tendencies.
This study is a preliminary attempt to analyze some of the features of such a conflict.

SUBJECTS AND PROCEDURE

Ninety-six recruits, all high-level candidates for pilot training, were divided randomly into two groups. The shock-only group consisted of $\mathbf{4 8}$ Ss awaiting an unavoidable electric shock to be given exactly $6 \mathrm{~min}$ following a threat. The task + shock group consisted of 48 Ss who, in addition, had to take an achievement test while anticipating the shock. Ss were tested individually in a soundproof room. They were attached to a Galileo Polyanalyser Model PA 8a. The autonomic index that was measured was heart rate, using a Reflex Plethysmograph transducer attached to the thumb of the nondominant hand. The shock electrodes were attached to the back of the same hand. Shock was administered through a self-made electroshock with approximate intensity of $100 \mathrm{~V}$. Duration of shock was approximately $1 \mathrm{msec}$.

The Ss had earphones and a microphone. All communication was via an intercom system. Ss sat by a small table facing a clearly visible clock. Their dominant hands were free for use in the achievement task.

\section{INSTRUCTIONS}

In the shock-only group, Ss were attached to the instruments and given a $2 \cdot \mathrm{min}$ period of baseline recording. Following this period, they were told that they were taking a test of behavior under stress, that exactly 6 min following a starting signal they would be given a strong electric shock, and that their task was to observe the clock closely.

The task + shock group was pretested with the task before entering the physiological laboratory. The task consisted of visual screening of a page of random numbers, checking the occurrences of a particular number as quickly as possible. Following this task, they were attached to the polygraph and received the same instructions as the shock-only group. In the fourth minute of anticipation, they were given another visual screening task of the same type but using different numbers. The task was finished exactly $5 \frac{11}{2} \mathrm{~min}$ after the starting signal, i.e., $30 \mathrm{sec}$ before the shock was due.

Ss in the task + shock group received the task as relevant to the testing for pilot training, which turned it into a stressful task.

\section{RESULTS AND DISCUSSION}

The dependent variable in this study was heart rate. Every single heart beat was counted, and the relevant measures were transformed into scores 


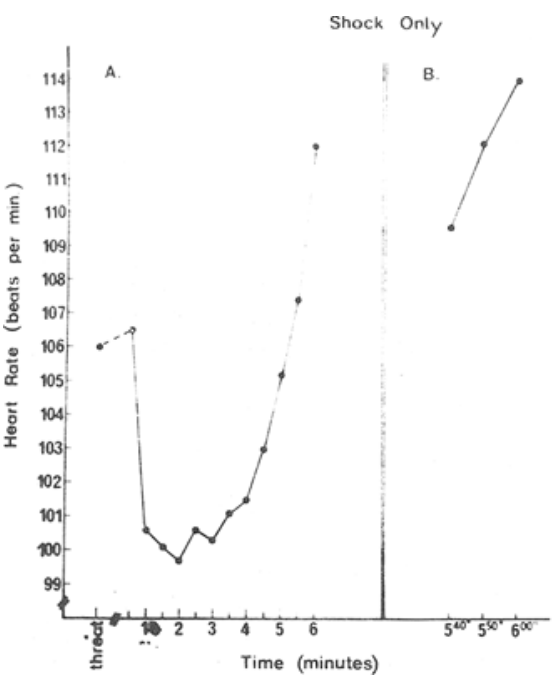

Fig. 1. Mean heart rates for the entire period of anticipation of the shock only group.

of beats per minute. Part A of Figs. 1 and 2 presents the mean heart rates of the two groups for every 30 sec of the anticipation period.

The readings of "threat" were obtained by transforming into beats per minute the total number of beats during the shock instructions. Figure 1 demonstrates again the expected U curve. In Fig. 2, the stressful effect of the task itself can be observed. During the task itself, there is some relaxation, which is particularly prominent with the termination of the task, with the result that the mean heart rate during the last $30 \mathrm{sec}$ prior to the shock is lower than during the whole testing period.

A closer inspection of this phenomenon was made by analyzing the critical $30 \mathrm{sec}$ more exactly. Part B of Figs. 1 and 2 presents the heart rate for every $10 \mathrm{sec}$ of this critical period. As can be seen in the shock-only group, the fear reaction grows progressively with the coming of the shock, whereas the opposite happens in the task + shock group. A nonparametric comparison was made between the heart rate of the $51 / 2 \mathrm{~min}$ and the last $10 \mathrm{sec}$ of anticipation for each group. The distribution of Ss according to this comparison and according to groups appears in Table 1. Computing the dependence between the two variables, it was found to be highly significant $\left(x^{2}=33, \quad d f=1, \quad p<.001\right)$. Of the most interest is the comparison of the absolute levels of fear reaction during the last $10 \mathrm{sec}$ in the two groups. A median test was once again used, and the distribution of Ss appears in Table 2. Table 2 indicates that when the shock is imminent, the heart rate in the shock-only group is systematically higher than it is in the task + shock group $\left(x^{2}=10.6, \mathrm{df}=1\right.$, $\mathrm{p}<.01$ ). (Five Ss who had the median score exactly were eliminated from the test.)

The dramatic effect of the termination of a stressful task upon subsequent fear reaction was, to a large degree, unexpeted. It appears that in the conflict between relaxation from the stress that has passed and fear from the stress that is due, the relaxation tendency prevails. The exact timing of the termination is probably a crucial factor. In an unpublished MA thesis, Eshel (1970) found that when the stresstul task is terminated $60 \mathrm{sec}$ prior to the shock, a relaxation takes place that is subsequently followed by a rise in heart rate. This produces the U curve within the last minute of anticipation. In the shorter, 30-sec interval, only the first half of the $U$ can be detected.

Table 1

Comparison of Heart Rate of Min 5//2 With That of Last $10 \mathrm{Sec}$ for the Two Groups

\begin{tabular}{lccc}
\hline & $\begin{array}{c}\text { Accele- } \\
\text { ration }\end{array}$ & $\begin{array}{c}\text { Decele- } \\
\text { ration }\end{array}$ & Total \\
\cline { 1 - 4 } Shock Only & 36 & 12 & 48 \\
Task + Shock & 8 & 40 & 48 \\
Total & 44 & 52 & 96 \\
\hline
\end{tabular}

Table 2

Median Test for the Heart Rate During the Last 10 Sec in' the Two Groups

\begin{tabular}{lccc}
\hline & $\begin{array}{c}\text { Above } \\
\text { Median }\end{array}$ & $\begin{array}{c}\text { Below } \\
\text { Median }\end{array}$ & Total \\
\hline Shock Only & 31 & 16 & 47 \\
Task + Shock & 14 & 30 & 44 \\
Total & 45 & 46 & 91 \\
\hline
\end{tabular}

The relatively long duration of deceleration should not be confused with that reportedly taking place in the last $2-3$ sec before a predictable shock (Deane, 1966; Graham \& Clifton, 1966; Folkins, 1970). That deceleration is controlled by the approaching negative stimulus, whereas the effect reported here is controlled by past experience, in spite of the future.

Since we did not use a beat-to-beat heart rate recorder, we could not measure this short-term effect, nor was it possible to score the intensity of response to the shock itself.

There is not sufficient information upon which to base a comprehensive explanation for this effect, and it ought to be demonstrated in other experimental contexts. Our tentative guess is that while a person is in the process of relaxing (in contrast to the state of being relaxed), everything, even future dangers, looks less threatening to him. In a sense, his appraisal of the threats changes (Lazarus, 1966). This tendency towards greater confidence may be intensified by the physiological feedback of "feeling better," "calming down," etc. These matters ought, however, to be tested explicitly. In addition to their theoretical interest, they have vast potentially practical implications.

\section{REFERENCES}

BREZNITZ, $S$. Incubation of threat: Duration of anticipation and false alarm as determinants of the fear reaction to an unavoidable frightening event. Journal of Experimental Research in Personality, $1967,2,173-179$.

BREZNITZ, $\mathbf{S}$. "Incubation of threat" in a situation of conflicting expectations. Psychological Reports, 1968, 22. 755-756.

DEANE, G. E. Human heart rate responses during experimentally induced anxiety: Effects of instructions on acquisition Joumal of Experimental Psychology. 1966, 67, 193-195.

ELLIOT, R., BANKART, B., \& LIGHT, T. Differences in the motivational significance of heart rate and palmar conductance: Two tests of a hypothesis. Journal of Personality \& Social Psychology, 1970, 14, 166-172.

ESHEL, M. The effect of second stress placement upon the fear reaction to an ongoing stress. Unpublished MA thesis. Hebrew University, Jerusalem, 1970.

FOLKINS, C. H. Temporal factors and the cognitive mediators of stress reaction. Journal of Personality \& Social Psychology, 1970, 14, 173.184.

GRAHAM, F. K., \& CLIFTON, R. K. Heart rate change as a component of the orienting response. Psychological Bulletin, 1966, 65, 305-320.

LAZARUS, R. S. Psychological stress and the coping process. New York: McGraw-Hill, 1966.

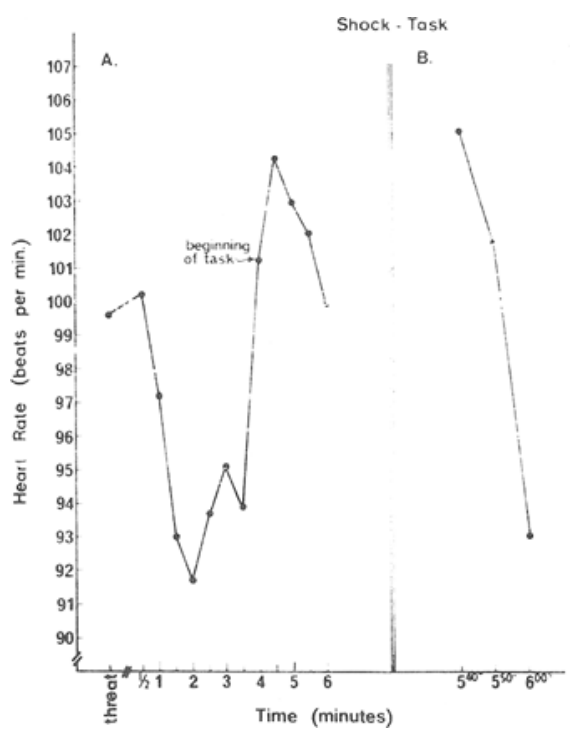

Fig. 2. Mean heart rates for the entire period of anticipation of the shock + task group. 